\title{
Mobile Ambulatory Application Asafny and Traditional Phone Request 997: A Comparative Cross-Sectional Study
}

This article was published in the following Dove Press journal: Open Access Emergency Medicine

\section{Arwa Althumairi (ID \\ Zainab Alnasser (iD \\ Sarah Alsadeq \\ Nouf Al-kahtani (iD \\ Afnan Aljaffary (D)}

Health Information Management and Technology (HIMT) Department, College of Public Health, Imam Abdulrahman Bin Faisal University, Dammam, Saudi Arabia
Correspondence: Arwa Althumairi Health Information Management and Technology (HIMT) Department, College of Public Health, Imam Abdulrahman Bin Faisal University, Dammam, Saudi Arabia Tel +966 I33335213

Email aalthumairi@iau.edu.sa
Purpose: This study aimed to determine whether there was a time difference between the ambulatory application Asafny and traditional type 997 in reaching people in need and interacting appropriately.

Materials and Methods: This study was conducted using retrospective cross-sectional study. A total of 2120 ambulance requests was extracted from Saudi Red Crescent Authority servers in Eastern Province, Kingdom of Saudi Arabia. The requests were extracted between 2017 and 2019. Results: There were no significant differences between the two methods of request. In 2019, the shortest times for all phases of requests were recorded. "Ordinary patient" was the most common cause for requests.

Conclusion: Over the years, efforts by the Saudi Red Crescent Authority facilitated improvements in ambulatory services by adapting new technology and services. This has helped reduce times for all phases of emergency requests.

Keywords: 997, ambulances, Red Cross, Saudi Arabia, reaction time, emergency service, hospital, Asafny, Saudi Red Crescent Authority, mobile applications

\section{Introduction}

Long ambulance response times have contributed to thousands of deaths worldwide. Delayed reactions endanger the lives of people. Udawant et al (2017) found that individuals died due to the inaccessibility of proper and timely treatment. ${ }^{1}$ Even in South Asia, there were recommendations to strengthen emergency medical services with the aim of reducing the number of needless deaths and disabilities by improving emergency medical services. ${ }^{2}$ A systematic random sample of people in Greater Manchester, UK who requested an ambulance by dialing 999 was performed to determine the acceptability of their emergency medical dispatch system and measure callers satisfaction of the service. ${ }^{3}$ Carvalho focused on improving the effectiveness and efficiency in the emergency medical responses by solving dispatch and relocation ambulance problems that he believed impacted on the health status of those who called for ambulances. ${ }^{4}$ For Saudi Arabia, a comparison of Asafny and the 997 system has not yet been reported. Therefore, in the present paper, we compared these common ambulance services in terms of response times in Saudi Arabia.

\section{Background}

The Saudi Red Crescent Authority (SRCA) was established on 1/16/1963 Hijri by Royal Decree to provide emergency medical services (EMS) in all administrative 
regions of the kingdom of Saudi Arabia for both Saudi citizens and foreigners by calling 997. It also provides services such as training programs, volunteering, and conferences. SRCA has 66 ambulatory centers in Eastern Province with a connection of 44 hospitals, which helps to contact the hospital system before reaching the hospital to prepare for arriving patients.

Currently, technology has evolved and contributed to improve health services. In 2016, the Saudi Red Crescent Authority initiated Asafny and it began operating in 2017. Initially, the focus of the Asafny Application was deaf and non-Arabic speaking people. The application has a number of features, including saving patient personal and health information in the application so that whenever they face an emergency situation, they can call an ambulance using the application and the Red Crescent Authority can directly access their information and location to save time. The third method for ordering an ambulance is the "SOS," which stands for Save our Souls. The SOS application is already installed in iPhone devices, allowing automatic calls to local emergency number in the country with the patient's current location.

\section{Context}

Ambulances were established decades ago to assist people during emergency situations. They are required to attend to the injured regardless of the location of the incident. These vehicles observe specified routing strategies that at times lack efficiencies due to a number of reasons, including an increased number of emergency incidents and the occurrence of many requests. Despite the existence of significant technological and scientific developments in the healthcare sector over recent decades, increased demand for ambulance services exists in which the people are more exposed to the risk of illness due to rises in diseasecausing factors, including longevity, sedentary behavior, violence, and diseases associated with aging; the increased risk has resulted in a rise in demand for emergency services, with ambulance response times being a key factor affecting overall quality of care. ${ }^{5}$ Several studies have investigated the various ways to increase ambulance services efficiency. For example, $\operatorname{Sar}^{6}$ found that the Segment Effect Value formula, a GIS navigation approach, is crucial in directing and guiding the movement of ambulances, as it enables them to achieve acceptable ambulance response times (ARTs). ${ }^{6}$ These findings are consistent with those of previous studies that indicated that geospatial time analysis of ambulance deployment is associated with reduced response times. $^{7}$

The routing of ambulances triggered studies concerning their reallocation. The deployment of the locations of emergency vehicles determines their availability and effectiveness in reducing response times. ${ }^{8}$ According to Nogueira, Pinto, and Silva (2016), ${ }^{8}$ the ambulance quantity and base locations influence the performance of EMS. ${ }^{8}$

In the UK, emergency vehicles have failed to realize their response time targets for both possible and actual life-threatening calls. Consequently, investigators have performed studies to produce measures of improving this condition; according to Slater (2017), ${ }^{9}$ the use of alternative secondary and tertiary resources enables ambulance services to achieve the response time targets. ${ }^{9}$ Another study that adopted a simulation model based on action learning revealed that an ambulance service must shift from the nearest crew response model to one that allows for a specified multi-organizational service to definite need categories. ${ }^{9}$ These findings suggest that ARTs are achievable, subject to the institution of appropriate policies.

A considerable number of studies have investigated the means of lowering ARTs. Typically, governments have a prespecified duration within which an emergency vehicle should arrive at the location of the incident. However, they are considering reducing these time limit targets. According to research, this move would improve patient care, because lowering ARTs increases survival rates. ${ }^{10}$

Technological deficits are leading factors affecting emergency medical responses in various parts of the world. Consequently, ambulances experience delays that ultimately adversely affect quality of life of the callers. Various technological interventions have been developed to overcome these limitations. Gupta developed a smart ambulance system and found that the internet of things and smartphone technologies could reduce time complexity and enable the provision of faster provision of medical services. ${ }^{1}$ Kobayashi, Kimura, and Kenichi developed a smart ambulance approach alarm system model and discovered that technology is key to the minimization of traffic on roads. ${ }^{11}$ These findings suggest that the consideration of the optimal ARTs improves healthcare and save lives. Fitch $(2005)^{12}$ found that measuring performance, responding to ambulance requests in a professional appropriate way, meeting the supply with the demand, and applying technology are all factors that could improve response time performance. ${ }^{12}$ 
The Red Crescent Authority in Saudi Arabia developed a mobile application called Asafny to support 997 emergency call services. Despite the development of this technology, some people still insist on using 997. The reasons for this are mainly the lack of internet access for some people. The 997 system and Asifny were both established to provide people in need with ambulance care quickly to save lives. Comparing these two systems will help identify limitations or strengths in both emergency methods, and will thereby support the Ministry of Health in achieving their aim of saving lives. Ambulance centers are distributed based on the vision and mission of the Saudi Red Crescent Authority to achieve the priority aim of serving and saving patients by reducing response times so as to reduce disabilities and to keep individuals active in the community. ${ }^{11}$ According to recent statistics at the Saudi Red Crescent Authority website, the Eastern Province has a number of 171 ambulance vehicles. A comparison of these two ambulatory request methods has not been previously reported. This research topic was addressed due to the lack of SRCA information regarding 997 and Asafny in the literature.

\section{Aims and Objectives}

We aimed to quantify the time differences of requests by year and the common causes of requests along with their response times for both Asafny and 997.

At the end of the study, we determined whether to accept our hypothesis that ambulance arrival times triggered by the mobile ambulatory application Asafny would be similar to those of the traditional 997 call requests. The null hypothesis was that ambulance arrival times triggered by the mobile ambulatory application Asifny would be different from those triggered by traditional 997 phone calls.

\section{Materials and Methods Research Design}

This study was based on a quantitative research methodology using a comparative retrospective cross-sectional research design. This method was used to facilitate collecting data in a short period of time and to provide us with an initial status of the ambulatory services as well as opportunities for improvements. The independent variable was the method of ambulance request whether by the mobile ambulatory application Asafny or traditional phone request (997). There are two categories of dependent variables: the first one is the characteristics of the ambulance requester that is the cause of requests. The demographics of the people included in this study were amended by the data source to maintain the privacy of individuals; the other dependent variables are related to the request itself, and include the year of request, the time from accepting the request until arriving at the accident/emergency location, the time from leaving the accident location until arriving to the hospital, and the time from arriving at the accident location until closing the case for home-treated patients.

\section{Study Setting}

A retrospective data collection was conducted from all the emergency requests in Eastern Province between 2017 and 2019 by the Red Crescent Authority. The data can be obtained at The Saudi Red Crescent Authority website (https://www.srca.org.sa/en). The Red Crescent Authority in Saudi Arabia was established in 1963. It is the only body throughout the Kingdom that provides emergency ambulance services by contacting the hotline number 997 and ordering an ambulance. The General Center is located in Riyadh city, and 459 branches are distributed in large cities. The divisions of branches were established in various locations within the large cities based on branch manager decisions. ${ }^{13}$ The reporting systems for each large city are separate from one another, while backup for all ambulatory requests is maintained in the General Center in annual report format. Some of the services provided by the authority include providing necessary urgent aid in accidents, transporting the injured to governmental and contracted hospitals, training the hospital employees and volunteers for emergency situations, and auxiliary body for medical departments in war. Since 2017, the Red Crescent Authority adopted the Asafny application to facilitate ordering ambulances for deaf, mute individuals and non-Arabic speakers. It is important to mention that this is not an alternative to the traditional 997 system.

\section{Study Data (Ambulance Request)}

The study data were extracted from 2017 (the start year of Asafny) up to 2019. A clustered random sample of people who ordered ambulances in Eastern Province, Kingdom of Saudi Arabia (KSA) has been taken from each year based on a averaging the number of requests. The inclusion criteria were all 997 and Asafny requests including home-treated cases. The exclusion criteria were cancelled requests and those missing data, for example times of the request, date, 
reasons. "Save Our Souls" (SOS) requests were excluded from this study because this service is provided to certain mobile phone types only and it is not directly delivered by SRCA.

\section{Data Collection Methods}

All ambulatory requests are served by the Red Crescent Authority (a copy of a sample of data variables is found in Tables 1 and 2). The data regarding ambulatory services are kept in a different server. These servers were meant for different ambulatory requests (Asafny and 997). The model for the ambulance request processes are illustrated in Figure 1. We believe data were saved for quality, judicial, or political issues; therefore, these are considered secondary data.

\section{Instruments}

The data were extracted from Saudi Red Crescent Authority servers. This is the optimal way to obtain the data because it is difficult to follow up all cases, especially when they are related to sensitive situations, times, and geographical areas. One of the challenges faced is the data cleaning process, because the date and time formats for the different emergency methods (Asafny and 997) are different.

\section{Procedure and Timeline}

The data were requested from the Red Crescent Authority in the Eastern Province after face-to-face meetings with the Eastern Operations Department Manager to clarify the project and its aims. This study measures four time differences involved in ordering an ambulance, as follows: 1) accepting the order until reaching the requester location; 2) reaching the location to leaving the location; 3) leaving the location until reaching the hospital; and 4) total time from accepting the order until closing the case. "Reaching the location to leaving the location" was the longest time period for both methods of ambulance request. Before the analysis stage began, data cleaning and missing data checks were carried out. These included deleting blank and duplicated rows, as well as calculating the differences between the time phases. (the Excel calculation is attached in Table 1 and 2 and Figure 2)

\section{Analysis}

The study involved some collection of data taken by the ambulatory service providers when responding to requests and calls from the public when needed. The collected data were cleaned in Excel and then entered into a Statistical Package for the Social Sciences (SPSS) v 25 Armonk,NY. for further analysis. The analysis involved describing request characteristics using percentage, mean and standard deviation (SD), presenting the patterns of request by years from 2017 to 2019, and comparing the type of requests using descriptive statistics. After running normality tests, the data skewness were between -2 and 2 , representing normally distributed data. Therefore, parametric data analysis was used for the current study.

\section{Results}

A total of requests $871(39 \%)$ and 1249 (61\%) were extracted for Asafny and 997, respectively. The mean (SD) of total times from accepting orders until closing the case were similar for Asifny and 997 (Table 3). For all time phases, the Asafny SD was ( $<1$ Min), which was shorter than that of 997 requests that varied from one phase to another. Accepting the order until reaching the requester location recorded was less than a mean of 14 in Asafny (13 minutes), compared to 14 minutes for 997. Reaching the location until leaving the location recorded the highest mean that was exactly the same for both methods of ambulance requests (mean $=00: 17$ ), and 997 present the highest values of $\mathrm{SD}=(00: 33)$ and Median $(I Q R)=00: 13(0: 14)$. The time for leaving location until reaching the hospital for the Asifny application was less than 1 minute, as recorded for accepting order until reaching the requester location; however, with mean $=00: 08$ for 997 requests, the highest variance in median

Table I How the Data Been Sorted in the Red Crescent Centre

\begin{tabular}{|c|c|c|c|c|c|c|c|c|c|}
\hline A & B & C & D & E & $\mathbf{F}$ & G & $\mathbf{H}$ & I & J \\
\hline $\begin{array}{l}\text { Order } \\
\text { No. }\end{array}$ & $\begin{array}{l}\text { Order } \\
\text { Acceptance }\end{array}$ & $\begin{array}{l}\text { Ambulance } \\
\text { Moving }\end{array}$ & $\begin{array}{l}\text { Reaching } \\
\text { the } \\
\text { Location }\end{array}$ & $\begin{array}{l}\text { Leaving } \\
\text { the } \\
\text { Location }\end{array}$ & $\begin{array}{l}\text { Reaching } \\
\text { the } \\
\text { Hospital }\end{array}$ & $\begin{array}{l}\text { Leaving } \\
\text { the } \\
\text { Hospital }\end{array}$ & $\begin{array}{l}\text { Close } \\
\text { the } \\
\text { Case }\end{array}$ & $\begin{array}{l}\text { Type of } \\
\text { Injury }\end{array}$ & $\begin{array}{l}\text { Reason of } \\
\text { Cancelation }\end{array}$ \\
\hline 1911 & $\begin{array}{l}\text { I I/03/1439 } \\
03: 24: 00 \\
\text { PM }\end{array}$ & $\begin{array}{l}\text { II/03/1439 } \\
\text { 03:23:49 PM }\end{array}$ & $\begin{array}{l}\text { II/03/I439 } \\
02: 59: 25 \\
\text { PM }\end{array}$ & $\begin{array}{l}\text { II/03/ } \\
\text { I439 } \\
02: 49: 21 \\
\text { PM }\end{array}$ & $\begin{array}{l}I 1 / 03 / 1439 \\
02: 30: 59 \\
\text { PM }\end{array}$ & $\begin{array}{l}\text { II/03/ } \\
\text { I439 } \\
02: 21: 16 \\
\text { PM }\end{array}$ & $\begin{array}{l}\text { II/03/ } \\
\text { I439 } \\
02: 21: 15 \\
\text { PM }\end{array}$ & $\begin{array}{l}18 \\
\text { Respiratory } \\
\text { crisis }\end{array}$ & \\
\hline
\end{tabular}




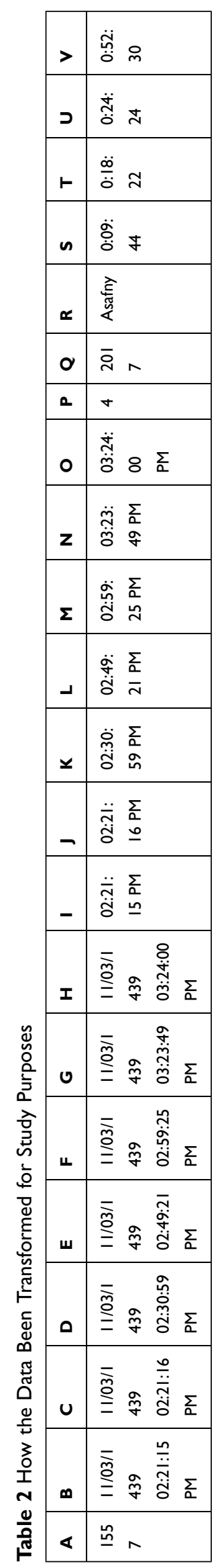

(IQR) between the methods of ambulance requests was recorded in which the Asafny application recorded shorter median (IQR) $(00: 06$ (0:11)), and the Asifny had the range time $(<1$ Min - 2:03) compared with the remaining Asifny phases. The total time from accepting order until closing the case had a lower mean and median (IQR) for Asafny with mean 00:36 median $=(00: 32$ $(0: 17))$ compared to 997 mean $=00: 38$, median $(00: 33$ $(0: 22))$. In this phase, the maximum time and SD for 997 was $(<1$ Min - 4:27) and (00:46) and Asifny was $(<1$ Min $-4: 19)$ and $(00: 1)$ which was shorter than that of 997.

The time taken by the service providers was between 33.08 and 40.0 minutes from accepting order until closing the case for all years (Figure 3). The years 2017 and 2018 recorded 40 minutes from accepting order until closing the case, while in 2019 , the time decreased to 33.08 minutes. The service providers took the shortest time from leaving the location of accident until reaching to the hospital, between 6.9 and 8.1 minutes, with the year 2018 recording the longest time ( 8.1 minutes). Slightly more time was taken from accepting order until reaching the requester location: between 10.07 and 16.06 minutes; the year of 2017 recorded the longest time interval. Much of the time was taken by the service providers from reaching location until they leave the location, between 15.8 and 18.14 minutes; the year 2018 recorded the longest time interval (18.14 minutes compared with 15.8 in 2017). As noted, the year of 2019 recorded the shortest time for all phases compared with 2017 and 2018.

The top ten types of injury for ambulatory requests are summarized in Table 4. The table details the types of injuries, their corresponding numbers, and time taken by the ambulatory service providers to respond. Ordinary patient requests were the predominant type, which recorded the largest number of 730 (35\% of total cases) during the study period. This was followed by crash accidents with 319 (15.4\%), while the least requested case types were run over and violence with the smallest numbers of $47(2.3 \%)$ and $43(2.1 \%)$, respectively.

T-tests were carried out to check for significant differences between arrival times for Asafny and 997. The test gave a p-value of 0.099 . This is sufficient evidence to accept the null hypothesis and conclude that there is no significant difference between method of request: Asafny (mean $=00: 36, \mathrm{SD}=00: 25)$, and 997 (mean $=00: 38, \mathrm{SD}=$ 00:27), with $\mathrm{t}(2064)=-1.65$, p-value $0.099,95 \%$ CI (-0:04: 18.16, 0:00: 22.249). 


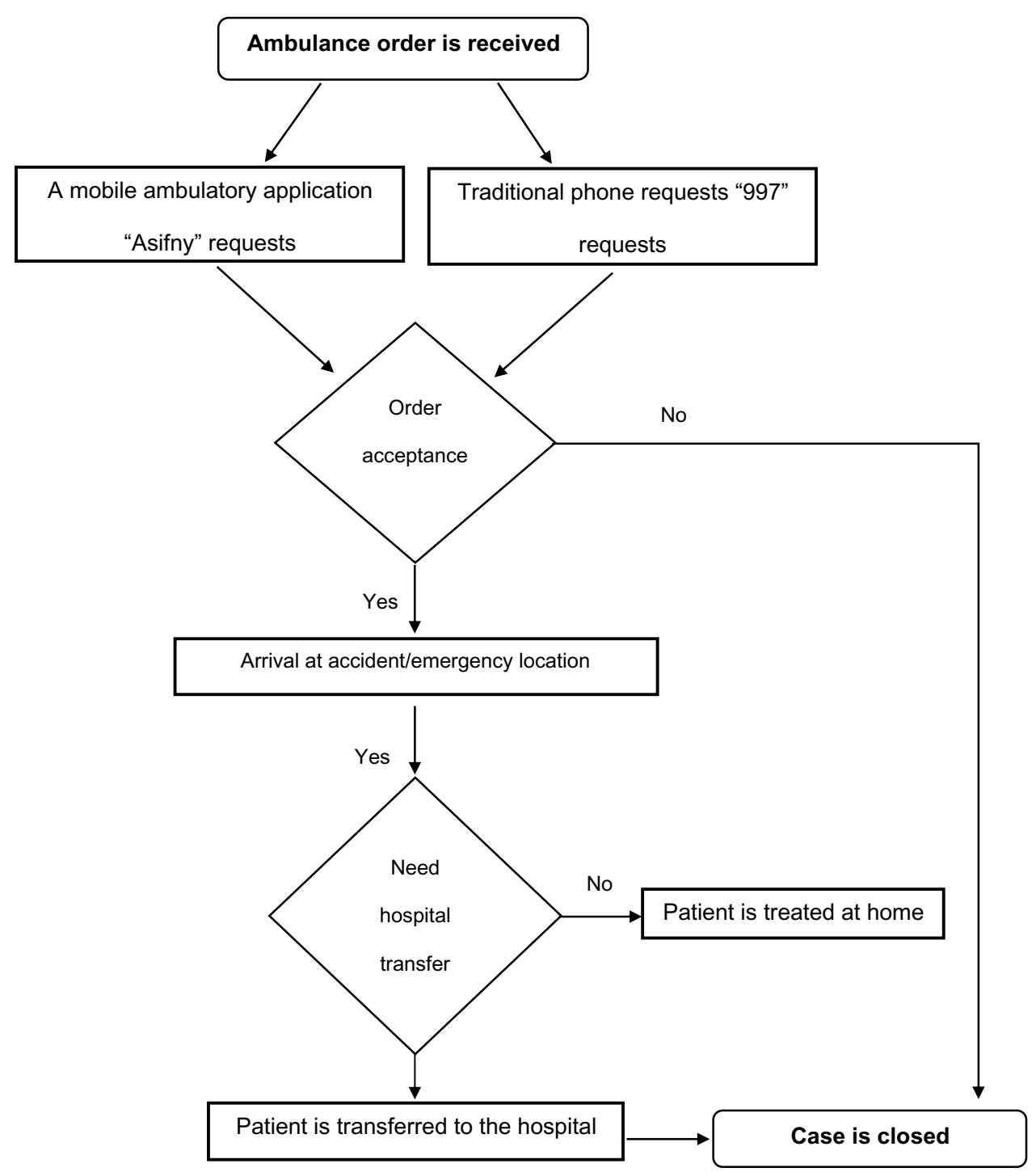

Figure I The flowchart of ambulance requests.

\section{Discussion}

This comparative cross-sectional study aimed to compare the mobile ambulatory application Asafny and the traditional phone request 997 . There was no significant difference between the two methods, suggesting that the Red Crescent Authority answers emergency requests without differences in response time, meaning that both request routes are handled equally. This was expected because the SRCA was using the same process after receiving requests as illustrated in Figure 1. The only differences were found for the time of information gathering from the requester. Assessing the distributions of requests by different time phases in minutes and years of the request showed that the year 2019 recorded the shortest time for all phases in requests compared to
2017 and 2018. This suggests that services are being provided in response to requests more quickly, indicating continuous improvement of SRCA over time. A considerable number of studies investigated the means of lowering ambulance response times, so as to increase survival rates. ${ }^{1}$ Further studies are needed to compare survival and mortality rates based on ambulance response times between Asafny and 997.

The top type of injury for the most common request was "ordinary patients." We suggest narrowing "ordinary patient" to more specific terms, because as is, it is an overly broad term. This might gather non-emergent cases that consume substantial time and effort on the part of emergency care that should be delivered to more severe cases. 


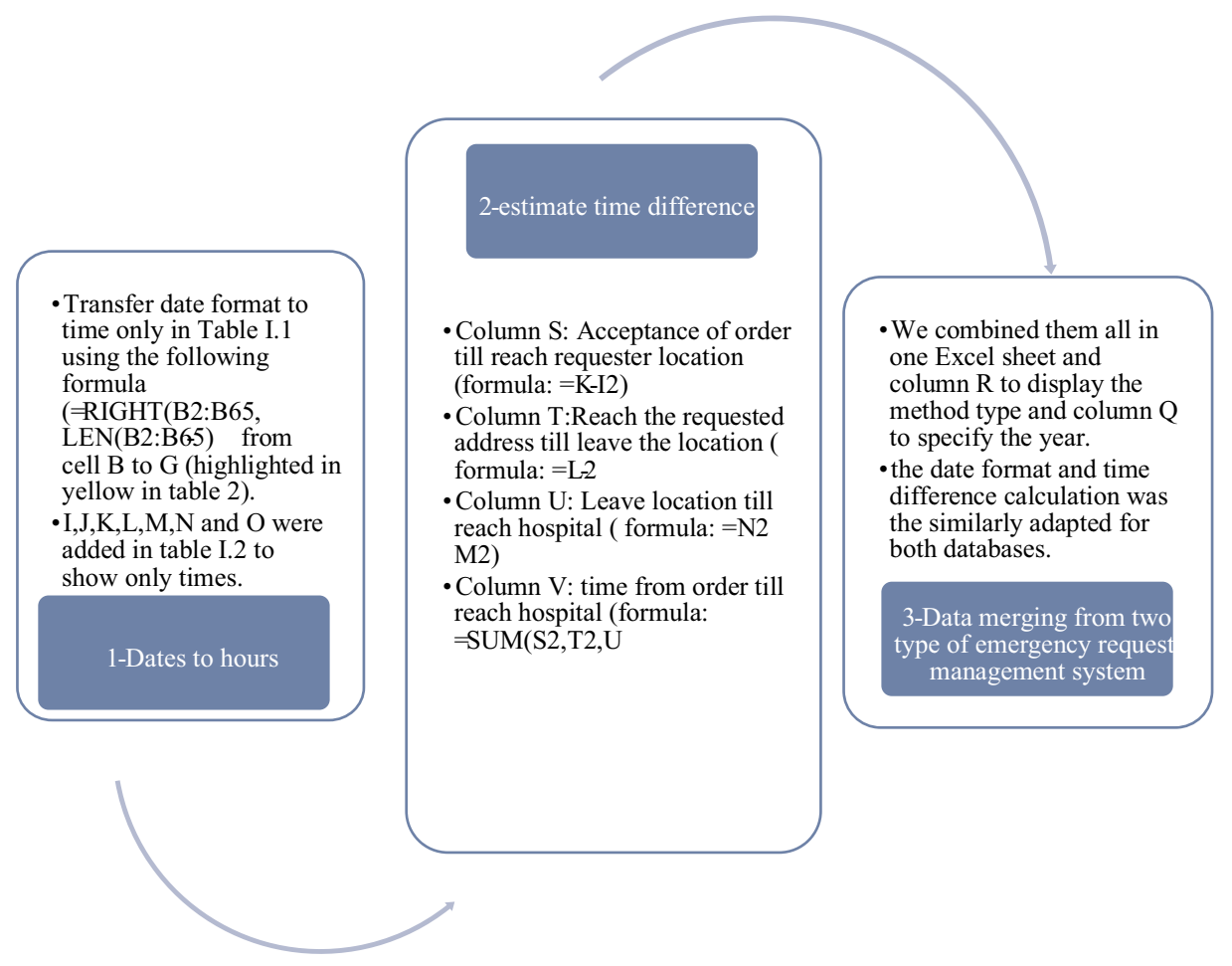

Figure 2 Descriptions of database cleaning process.

It could be explained that there were a number of barriers that accounted for time taken, including the dangerousness of the location, whether the injured individual was trapped in a car or a closed place, in a private secure site where they needed authorization to obtain access, or if they were taking care of the case and trying to stabilize the patient's condition. Lam mentioned several barriers to ambulance response time in Singapore and one of them was the place of incident which affected ARTs. ${ }^{14}$
Ambulances should assist people in emergency cases regardless of their location. Therefore, efficient routing of the ambulance is important. A study found that a GIS navigation approach could guide the movement of the ambulance resulting in acceptable ARTs. ${ }^{1}$ Saudi paramedics are provided with tablets that allow them to sign each phase in the case with its appropriate time. The tablets have their own application to navigate the paramedic to the requester location; however, sometimes it does not

Table 3 Comparison of Means Between Asafny and 997

\begin{tabular}{|c|c|c|c|c|c|c|}
\hline \multirow[t]{2}{*}{ Time Differences } & \multicolumn{3}{|l|}{$\begin{array}{l}\text { Asafny } \\
N=87 \text { I (39\%) }\end{array}$} & \multicolumn{3}{|c|}{$\begin{array}{l}997 \\
N=1249(61 \%)\end{array}$} \\
\hline & Mean (SD) & $\begin{array}{l}\text { Minimum - } \\
\text { Maximum }\end{array}$ & $\begin{array}{l}\text { Median } \\
\text { (IQR) }\end{array}$ & $\begin{array}{l}\text { Mean } \\
(\mathrm{SD})\end{array}$ & $\begin{array}{l}\text { Minimum - } \\
\text { Maximum }\end{array}$ & $\begin{array}{l}\text { Median } \\
\text { (IQR) }\end{array}$ \\
\hline $\begin{array}{l}\text { Accepting order until reaching the } \\
\text { requester location }\end{array}$ & $00: 12$ (<1 Min) & $<1$ Min - 4:15 & $0: 09(0.06)$ & $\begin{array}{l}00: 13 \\
(00: 27)\end{array}$ & $<1$ Min $-3: 45$ & $\begin{array}{l}00: 10 \\
(0: 07)\end{array}$ \\
\hline Reaching location to leaving location & 00:17 (<1 Min) & $<1$ Min - 4:18 & $\begin{array}{l}00: 14 \\
(0: 11)\end{array}$ & $\begin{array}{l}00: 17 \\
(00: 33)\end{array}$ & $<1$ Min - 3:55 & $\begin{array}{l}00: 13 \\
(0: 14)\end{array}$ \\
\hline $\begin{array}{l}\text { Leaving location until reaching the } \\
\text { hospital }\end{array}$ & 00:07 (<1 Min) & $<1$ Min - 2:03 & $\begin{array}{l}00: 06 \\
(0: 11)\end{array}$ & $\begin{array}{l}00: 08 \\
(00: 24)\end{array}$ & $<1$ Min - 4:13 & $\begin{array}{l}00: 01 \\
(0: 12)\end{array}$ \\
\hline $\begin{array}{l}\text { Total time from accepting order until } \\
\text { closing case }\end{array}$ & $00: 36(00: 1)$ & $<1$ Min $-4: 19$ & $\begin{array}{l}00: 32 \\
(0: 17)\end{array}$ & $\begin{array}{l}00: 38 \\
(00: 46)\end{array}$ & $<1$ Min - 4:27 & $\begin{array}{l}00: 33 \\
(0: 22)\end{array}$ \\
\hline
\end{tabular}




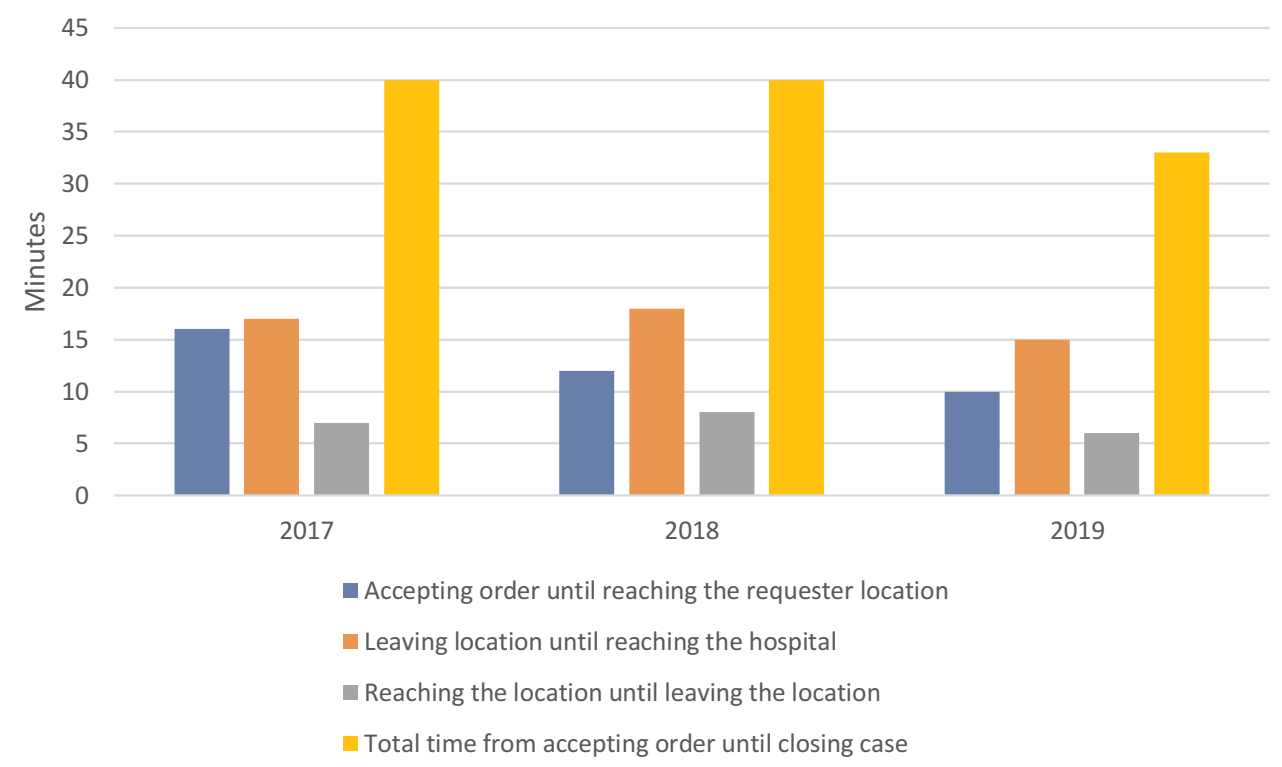

Figure 3 Distributions of requests according to phases, in minutes and year of the request.

work appropriately and it faces some technical issues. Therefore, in similar cases, the paramedics use their own Google Maps navigator or they rely on their own knowledge of the route and can reach the incident location in an appropriate time without the aid of an application.

Initiating a new application to order an ambulance is an intelligent way to reach those who cannot dial 997 for any reason, including inability to speak Arabic or English and deafness. In serious emergency situations, the application provides medical history and blood type, specifying any medication allergies of the requester. We wanted to

Table 4 The Top Ten Requested Cases

\begin{tabular}{|l|l|l|l|}
\hline Type of Injury & $\begin{array}{l}\text { Number of } \\
\text { Cases (\%) }\end{array}$ & Mean & $\begin{array}{l}\text { Minimum - } \\
\text { Maximum }\end{array}$ \\
\hline Ordinary patient & $730(35 \%)$ & $0: 38$ & $<1$ Min - 4:19 \\
\hline Crash accident & $319(15.4 \%)$ & $0: 34$ & $<1$ Min - 4:27 \\
\hline Fainting & $233(11.3 \%)$ & $0: 31$ & $0: 02-2: 49$ \\
\hline Respiratory crisis & $163(7.9 \%)$ & $0: 37$ & $0: 06-2: 44$ \\
\hline Fall & $128(6.2 \%)$ & $0: 38$ & $<1$ Min - 3:45 \\
\hline Epilepsy case & $84(4.1 \%)$ & $0: 33$ & $0: 01-1: 35$ \\
\hline Coma & $63(3.0 \%)$ & $0: 36$ & $<1$ Min - 1:44 \\
\hline Fire & $58(2.8 \%)$ & $0: 31$ & $<1$ Min - 2:25 \\
\hline Run over & $47(2.3 \%)$ & $0: 28$ & $<1$ Min - 0:49 \\
\hline Violence & $43(2.1 \%)$ & $0: 26$ & $0: 02-1: 09$ \\
\hline
\end{tabular}

measure the health status of the requester after reaching the hospital; the fact that we were unable to do this was one of the limitations of the study. The paramedic's responsibility ends after reaching the hospital without addressing whether the patient is alive or dead. Furthermore, we could not obtain data regarding the nationality or language of the requester due to the restriction of these data and their availability.

To conclude, we suggest adding a dropdown menu in the paramedic tablets to assign the state of the case at the time of reaching the hospital. In addition, a qualitative study is recommended to understand paramedic needs in order to provide rapid, improved emergency services in the KSA.

\section{Ethics and Limitations}

IRB approval was attained from the office of the Vice President for Research and Higher Studies, Imam Abdulrahman Bin Faisal University. The Institutional Review Board number was IRB -UGS-2019-03-395, approved on 12/18/2019. The data were aggregated, anonymized, and saved on a secure server. Any cells that constituted fewer than five cases were hidden to avoid breaching privacy.

One of the research limitations was the inability to know whether the patient survived for hospital-treated cases because the Red Crescent Authority ends its responsibility at the point of delivering the case to the hospital or aiding the case at its location. Some demographic 
information such as the age, gender, and nationality were not shared because these were considered highly secure data. Selection of the samples was based on randomly select requests, this might reduce the generalizability of the study results as cases and controls were matched only on year rather than reason of requests of personnel handling request entering.

\section{Conclusion}

The Saudi Red Crescent Authority (SRCA) provides ambulatory services across the country for both citizens and non-citizens in Saudi Arabia. It is designed to provide a hotline number (997) that individuals can call and obtain direct help. In line with technological advancements, SRCA adopted Asafny that enables deaf and mute residents to order an ambulance. This study highlighted that Asifny is equivalent to 997 in terms of response time. There is a promising improvement in response times year by year. The ambulatory request for ordinary cases might be better specified so as to determine whether they are urgent services. These recommendations are meant to inform individuals regarding the use of technology as well as to reach out to senior citizens. There is an urgent need to make the application user-friendly to all the citizens regardless of their age. The project's strength lies in use of adequate methods; however, a qualitative study should be used to identify the areas that need improvement. For future studies, it is suggested to compare Asafny and 997 in terms of survival and mortality rates based on ambulance response times.

\section{Abbreviations}

ARTs, ambulance response times; EMS, emergency medical services; GIS, Geographic Information Systems; HIMT, Health Information Management \& Technology; IoT, internet of things; IRB, Institutional Review Board; KSA, Kingdom of Saudi Arabia; SD, standard deviation; SOS, Save our Souls; SPSS, Statistical Package for Social Sciences; SRCA, Saudi Red Crescent Authority.

\section{Acknowledgments}

Many thanks to the Eastern Province Saudi Red Crescent Authority. Special thanks to the Eastern Operations Department Manager \& CIT, Eng. Saleh Ali Saleh AlAsfour and to the System Engineering Communication \& Information Technology Head Quarters, Eng. Akeel Yousef Alnwaiser, for giving us the opportunity to start this thesis and provided us with the data. We are also grateful to the paramedic Ammar Al Abadi, who answered our spontaneous questions and gave us a clear picture of how a paramedic works.

\section{Disclosure}

The authors report no conflicts of interest in this work.

\section{References}

1. Udawant O, Thombare N, Chauhan D, Hadke A, Waghole D. Smart ambulance system using IoT. In: 2017 International Conference on Big Data, IoT and Data Science (BID). 2017;171-176.

2. Sriram V, Gururaj G, Razzak JA, Naseer R, Hyder AA. Comparative analysis of three prehospital emergency medical services organizations in India and Pakistan. Public Health. 2016;137:169-175. doi:10.1016/j.puhe.2016.02.022

3. O'Cathain A, Turner J, Nicholl JP. The acceptability of an emergency medical dispatch system to people who call 999 to request an ambulance. Emerg Med J. 2002;19(2):160-163. doi:10.1136/ emj.19.2.160

4. Carvalho AS, Captivo ME, Marques I. Integrating the ambulance dispatching and relocation problems to maximize system's preparedness. Eur J Oper Res. 2020;283(3):1064-1080. doi:10.1016/j. ejor.2019.11.056

5. Booth FW, Roberts CK, Laye MJ. Lack of exercise is a major cause of chronic diseases. Compr Physiol. 2012;2(2):1143-1211. doi:10.1002/cphy.c110025

6. Sar1 F A GIS based new navigation approach for reducing emergency Vehicle's response time. Acil müdahale araçlarının müdahale zamanını azaltmak için CBS tabanlı bir navigasyon yaklaşım [Internet]. 2017; Available from: http://acikerisim.selcuk.edu. tr:8080/xmlui//handle/123456789/11423. Accessed November 10, 2020.

7. Ong ME, Chiam TF, Ng FS, et al. Reducing ambulance response times using geospatial-time analysis of ambulance deployment. Acad Emerg Med. 2010;17(9):951-957. doi:10.1111/j.1553-2712.2010.00860.x

8. Nogueira LC Jr, Pinto LR, Silva PM. Reducing Emergency Medical Service response time via the reallocation of ambulance bases. Health Care Manag Sci. 2016;19(1):31-42. doi:10.1007/s10729014-9280-4

9. An action learning approach to the question: are ambulance response time targets achievable? [Internet]. Available from: https://www.tandfonline. com/doi/full/10.1080/14767333.2017.1358315?casa_token=H0A-R_Zn Vb4AAAAA\%3A1x67AF2LI_vYWHnpFqJLTBHzu0B8Zeghwb C4q2IiZ0-4AkzF6ld3On2Uhmap2VxXpcTFze_ZkTR7xHfs. Accessed November 15, 2020.

10. Pell JP, Sirel JM, Marsden AK, Ford I, Cobbe SM. Effect of reducing ambulance response times on deaths from out of hospital cardiac arrest: cohort study. BMJ. 2001;322(7299):1385-1388. doi:10.1136/ bmj.322.7299.1385

11. Smart Ambulance Approach Alarm System Using Smartphone [Internet]. Available from: https:/www.jstage.jst.go.jp/article/tran sinf/E102.D/9/E102.D_2018OFL0003/_article/-char/ja/. Accessed November 10, 2020.

12. Fitch J. Response times: myths, measurement \& management. JEMS J Emerg Med Serv. 2005;30(9):47-56.

13. News Library - Saudi Red Crescent Authority [Internet]. Available from: https://www.srca.org.sa/en/Media/NewsArchives. Accessed November 10, 2020.

14. Lam SS, Nguyen FN, Ng YY, et al. Factors affecting the ambulance response times of trauma incidents in Singapore. Accid Anal Prev. 2015;82:27-35. doi:10.1016/j.aap.2015.05.007 


\section{Publish your work in this journal}

The Open Access Emergency Medicine is an international, peerreviewed, open access journal publishing original research, reports, editorials, reviews and commentaries on all aspects of emergency medicine. The manuscript management system is completely online

and includes a very quick and fair peer-review system, which is all easy to use. Visit http://www.dovepress.com/testimonials.php to read real quotes from published authors.

Submit your manuscript here: https://www.dovepress.com/open-access-emergency-medicine-journal 